\title{
EFFICACY OF TWO APPROACHES OF TRANSFORAMINAL EPIDURAL INJECTIONS IN PATIENTS OF LUMBAR RADICULOPATHY
}

\author{
Moazzam Ali, Rashid Iqbal, Majid Waseem*, Liaquat Ali**, Tahseen Talib, Maliha Khawar*** \\ Combined Military Hospital/National University of Medical Sciences (NUMS) Rawalpindi Pakistan, *Combined Military Hospital Multan/National University of \\ Medical Sciences (NUMS) Pakistan, ${ }^{* *}$ Fouji Foundation Hospital, Rawalpindi Pakistan, ${ }^{* * *}$ Pak Emirates Military Hospital/National University of Medical Sciences \\ (NUMS) Rawalpindi Pakistan
}

\begin{abstract}
Objective: To determine the efficacy of transforaminal epidural steroid injection (TFESI) using conventional versus Kambin's triangle approaches in patients of lumbar radiculopathy.

Study Design: Quasi experimental study.

Place and Duration of Study: Department of Pain Medicine, Combined Military Hospital Rawalpindi Pakistan, from Oct 2019 to Apr 2020.

Methodology: Eighty patients suffering from lumbar radiculopathy fulfilling the inclusion criteria were included in this study and were randomly assigned to undergo transforaminal epidural steroid injection using either conventional approach (group C) or the Kambin's triangle (group K) approach. Pain scores and patient satisfaction levels were recorded at 4 and 8 weeks after the procedure.

Results: In both groups, the pain score (group C pre-procedure NRS $=7.28 \pm 1.26$ vs post-procedure NRS $=2.14 \pm 0.81$, group K pre-procedure NRS $=7.33 \pm 1.16$ vs post-procedure NRS=2.70 \pm 0.94 ) and patient satisfaction improved 4 and 8 weeks after the procedure. The pain score $(p$-value $=0.21)$ and patient satisfaction score $(p$-value $=0.88)$ however were not significantly different between groups.

Conclusion: This study demonstrated that using conventional or Kambin's approach exhibits no difference in decreasing pain score or patient satisfaction level.
\end{abstract}

Keywords: Kambin's triangle, Lumbar radiculopathy, Pain relief, Subpedicular approach, Transforaminal epidural injection.

This is an Open Access article distributed under the terms of the Creative Commons Attribution License ( https://creativecommons.org/licenses/by-nc/4.0/), which permits unrestricted use, distribution, and reproduction in any medium, provided the original work is properly cited.

\section{INTRODUCTION}

Low back pain is one of the most common presenting complaint in of patients with chronic pain ${ }^{1}$. It is estimated that life time prevalence of low back pain is around $70-80 \%{ }^{1}$. Amongst low back pain, lumbar radiculopathy is a frequent diagnosis. The mainstay of management for radicular low back pain remains pharmacotherapy, physiotherapy and epidural steroid injection ${ }^{2}$. It is thought that the affected nerve root is inflamed due to release of local mediators therefore the use of steroids has shown benefit in this regard. For deposition of drugs, epidural space can be approached via inter-laminar, transforaminal and caudal routes. Transforaminal route is considered one of the safest and effective route for intervention (figure). This technique is gaining popularity over traditional techniques owing to its peculiar features such as less injectate, more specificity and deposition at the main pathology $y^{3}$. There are different methods to perform the transforaminal injection such as the conventional subpedicular approach, Kambin's infraneural approach, retro neural approach and the supraneural approach ${ }^{4}$. Every app-

Correspondence: Dr Moazzam Ali, Department of Pain Medicine, Combined Military Hospital Rawalpindi Pakistan

Received: 19 Nov 2020; revised received: 05 May 2021; accepted: 07 May 2021 roach has its inherent risks and complications ${ }^{5}$.

In literature, the commonly used technique is subpedicular approach 6 , where needle is advanced into the safe triangle to reach the epidural space under fluoroscopic guidance. This method is preferred because the drug can be deposited in the anterior extradural space between the posterior aspect of herniated discs and the anterior nerve root sheath in the anterior epidural space. There is minimum risk to dural puncture. Another technique which is gaining acceptance is the Kambin's approach described first by Kambin in $1972{ }^{7}$. This approach is considered to be safer as compared to the previous approaches with similar or better results. This technique is also termed as infraneural, retrodiscal or preganglionic approach.

A study by Park et al, compared the subpedicular and Kambin's approaches in patients of chronic low back pain and found decreased pain scores along with less complication rate in latter ${ }^{8}$. A similar study by Jeong et al showed better treatment results in Kambin's triangle approach ${ }^{9}$. Literature regarding this type of study is scarce in our part of the world.

The scope of our study was to compare the efficacy conventional subpedicular versus the newer Kambin's triangle approach in patients of chronic radicular 
lumbar back pain. The objective of this study was to compare, in terms of analgesic efficacy and patient satisfaction level, the subpedicular conventional approach with Kambin's triangle approach in patients of chronic low pain complaining of lumbar radicular pain.

\section{METHODOLOGY}

A total of 80 patients were enrolled in the study that were fulfilling the inclusion criteria. It was a double blind single center quasi-experimental study. It was conducted over a period of six months from October 2019-April 2020. The study was approved by hospital ethics review committee vide ERB no. 124/11/2020.

The sample size was calculated from a previous published study using WHO sample size calculator with power of study $80 \%$ and level of significance $5 \%$ (considering fall in NRS from $5.3 \pm 1.89$ to $4.0 \pm 2.58)^{10}$, which came out to be 80 .

Patients were randomized in two equal groups by lottery method. Patients that were included in the study were those who were suffering from chronic low back pain (aged 20-80 years) suspected to arise from lumbar nerve root compression by history taking, clinical examination or electromyography; and spinal stenosis on the relevant nerve root evidenced by magnetic resonance imaging (MRI). The exclusion criteria were patient refusal, use of anticoagulant agents, uncontrolled diabetes mellitus, drug allergies, local or generalized infection, senile patients, and history of previous injection at same site in last 3 months, use of analgesics other than prescribed to both groups.

In both approaches, after informed written consent, patients were made to lie in prone position. A pillow was placed under the iliac crest to reduce lumbar lordosis. After positioning of the fluoroscope the area of injection was prepared by disinfectant solution. Needle insertion point was anesthetized with local anesthetic. A 22 G spinal needle was used in every patient. All procedures were done under fluoroscope. The needle path was followed via fluoroscopy, and $1 \mathrm{~mL}$ of contrast material Omnipaque (iohexol, 300mg iodine per milliliter); was injected to confirm epidural flow and to avoid intravascular, intrathecal, or soft-tissue infiltration. Upon confirmation of reaching the intended injection site, anteroposterior and oblique radiographs were obtained to confirm distribution of the contrast material. All procedures were performed by consultant pain medicine assisted by trainee pain medicine. Pain score was recorded before the intervention (baseline) then after 4 weeks and 8 weeks. Efficacy of each techniques was assessed using Numeric rating scale (NRS) for pain and patient satisfaction level. NRS ranges from $0-10$ with 0 being no pain and 10 being worst imaginable pain while patient satisfaction ranges from 1-5 with 1 being highly satisfied and 5 being totally unsatisfied regarding procedure outcome.

Group C (Conventional Approach): In conventional approach, the safe triangle was used for needle insertion. Its boundary included the pedicle above, lateral border of vertebral body and outer margin of spinal nerve.

Group K (Kambin's Triangle Approach): In this technique, infraneural needle insertion was done in the Kambin's triangle with boundaries consisting exiting nerve root, superior border of caudal vertebra and traversing nerve root (figure).

Descriptive statistics were used to describe the results i.e. mean and standard deviation (SD) for quantitative variables while frequency and percentages for qualitative variables. Independent sample t-test was used to compare means. The $p$-value of $<0.05$ was considered as significant.

\section{RESULTS}

A total of 80 patients were studied with 40 in each group. The mean age in group $C$ was $50.05 \pm 12.45$ years, whereas in group $\mathrm{K}$ it was $46.95 \pm 13.43$ years. There was no statistically significant difference between two groups on basis of age ( $p$-value: 0.29$)$, gender ( $p$-value: 0.82 ) and BMI ( $p$-value: 0.14) (table-I). None of the patient suffered any serious complication and no patient was lost to follow-up. After intervention both groups showed significant decrease in pain score (group C pre-procedure NRS $=7.28 \pm 1.26$ vs post-procedure NRS $=2.14 \pm 0.81$, group K pre-procedure NRS

Table-I: Patient characteristics.

\begin{tabular}{l|c|c|c}
\hline Parameter & $\begin{array}{c}\text { Group } \\
\text { Conventional } \\
(\mathbf{n}=\mathbf{4 0})\end{array}$ & $\begin{array}{c}\text { Group } \\
\text { Kambin's } \\
(\mathbf{n = 4 0 )}\end{array}$ & $\begin{array}{c}\boldsymbol{p} \text { - } \\
\text { value }\end{array}$ \\
\hline Age (years) & $50.05 \pm 12.45$ & $46.95 \pm 13.43$ & 0.29 \\
\hline $\begin{array}{l}\text { Gender } \\
\text { (male: female) }\end{array}$ & $17: 23$ & $18: 22$ & 0.82 \\
\hline BMI $\left(\mathrm{kg} / \mathrm{m}^{2}\right)$ & $27.90 \pm 4.39$ & $29.50 \pm 5.13$ & 0.14 \\
\hline
\end{tabular}

Table-II: Pain score before and after procedure.

\begin{tabular}{l|c|c|c}
\hline & $\begin{array}{c}\text { Group } \\
\text { Conventional } \\
(\mathbf{n}=\mathbf{4 0 )}\end{array}$ & $\begin{array}{c}\text { Group } \\
\text { Kambin's } \\
(\mathbf{n}=\mathbf{4 0 )}\end{array}$ & $\begin{array}{c}\boldsymbol{p} \text { - } \\
\text { value }\end{array}$ \\
\hline $\begin{array}{l}\text { Mean Numeric } \\
\text { Rating Scale Pre }\end{array}$ & $7.28 \pm 1.26$ & $\begin{array}{c}7.33 \pm \\
1.16\end{array}$ & 0.85 \\
Procedure & $2.14 \pm 0.81$ & $\begin{array}{c}2.70 \pm \\
0.94\end{array}$ & 0.21 \\
\hline $\begin{array}{l}\text { Mean numeric rating } \\
\text { scale at 4 weeks }\end{array}$ & $2.63 \pm 1.03$ & $\begin{array}{c}2.50 \pm \\
1.20\end{array}$ & 0.62 \\
\hline $\begin{array}{l}\text { Mean numeric rating } \\
\text { scale at 8 weeks }\end{array}$ & \multicolumn{3}{|l}{} \\
\hline
\end{tabular}


$=7.33 \pm 1.16$ vs post-procedure NRS $=2.70 \pm 0.94)$ but there was no statistically significant difference between two groups, $p$-value 0.21 at 4 weeks and $p$-value 0.62 at 8 weeks (table-II). Similarly there was also no statistically significant difference between two groups in terms of patient satisfaction, $p$-value 0.88 at 4 weeks and $p$-value 0.72 at 8 weeks (table-III).

Table-III: Patient satisfaction after procedure.

\begin{tabular}{l|c|c|c}
\hline & $\begin{array}{c}\text { Group } \\
\text { Conventional } \\
(\mathbf{n}=40)\end{array}$ & $\begin{array}{c}\text { Group } \\
\text { Kambin's } \\
(\mathbf{n}=\mathbf{4 0 )}\end{array}$ & $\begin{array}{c}\boldsymbol{p} \text { - } \\
\text { value }\end{array}$ \\
\hline $\begin{array}{l}\text { Mean Patient } \\
\text { Satisfaction Score } \\
\text { at 4 weeks }\end{array}$ & $1.88 \pm 0.72$ & $1.90 \pm 0.78$ & 0.88 \\
\hline $\begin{array}{l}\text { Mean Patient } \\
\text { Satisfaction Score } \\
\text { at 8 weeks }\end{array}$ & $1.78 \pm 0.62$ & $1.73 \pm 0.60$ & 0.72 \\
\hline
\end{tabular}

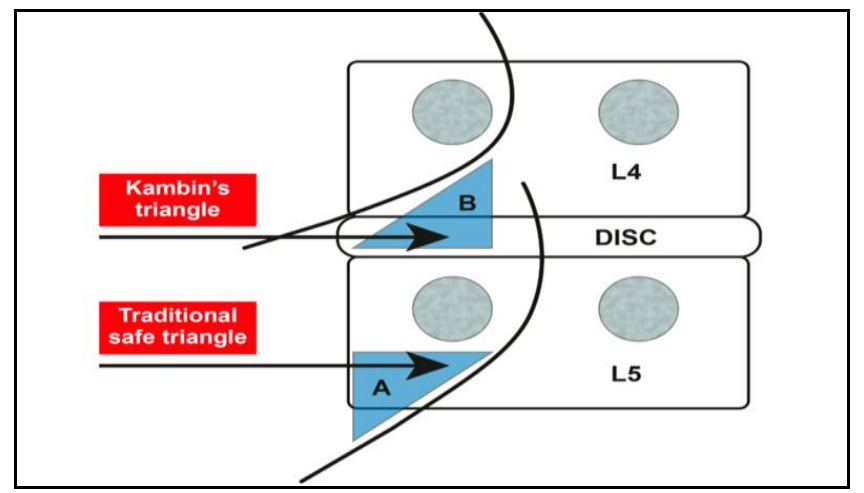

Figure: Approaches for transforaminal epidural injection.

\section{DISCUSSION}

Radicular pain is thought to occur due to mechanical nerve root compression as well as the presence of local inflammatory products in the epidural space ${ }^{11}$. It is pertinent to go for interventional pain management options incase conservative therapy fails to provide adequate pain relief to the patient ${ }^{12}$. Epidural injections are one of the commonly practiced injection techniques with fewer side effects. There are many techniques described in literature to access the epidural space but it is of paramount importance that the technique be employed should have maximum benefit for the patient. Transforaminal access for epidural space has a narrow safety window therefore every effort should be made that the approach used has good analgesic efficacy ${ }^{13}$. Using this technique it is ensured that the drug is deposited at the site of possible etiology. We hypothesized that the newer Kambin's triangle approach would be more effective as compared to the traditional subpedicular approach for transforaminal epidural injections.
In our study, we saw that both groups were comparable in terms of demography. The two approaches employed relieved pain adequately in all patients as revealed by decrease in numeric rating scale however no statistically significant difference was seen in mean pain score post procedure when followed up at 4 and 8 weeks. Similarly majority of the patients were satisfied with the result of intervention using either of the approaches but the satisfaction level between two groups had no significant difference.

Our study was in coherence with two different studies done by Park et al14,15. Their studies demonstrated that there was no difference between two approaches in terms of numeric scale and effectiveness scores. Another study by Jeong et al, also revealed similar results with no significant difference between two groups with regards to analgesic efficacy however in terms of short-term effects, the Kambin's approach had better effects ${ }^{16}$. A study by Lee $e t$ al, had somewhat different results as compared to our study. They observed that Kambin's approach had borderline more pain relief as compared to supraneural approach ${ }^{17}$. Same results were seen in a meta-analysis by Pairuchvej et al which showed that Kambin's approach has significantly better chance of effectiveness as compared to classical approach ${ }^{18}$.

Our study is first of its kind in our country. We attempted to single out the safest possible technique keeping in mind the efficacy of the intervention. Our study had a few limitations such as that we followed up patients for short term only that is for two months therefore more studies are needed to assess the long term results of these approaches. We did not study the correlation of other pain contributing factors like mental and social wellbeing. We took a limited sample size with strict inclusion criteria. We recommend that more randomized control trials are needed to decide which approach is the best with long term follow up.

\section{CONCLUSION}

The Kambin's triangle approach is an alternate approach for transforaminal epidural injections. Although the efficacy of both techniques do not differ significantly as revealed in our study, this newer injection technique can be an alternative to the traditional subpedicular approach incase substantial evidence is obtained.

\section{CONFLICT OF INTEREST}

This study has no conflict of interest to be declared by any author. 


\section{REFERENCES}

1. Imani F, Rahimzadeh $\mathrm{P}$, Khademi SH, Zamanabadi MN, Sadegi $\mathrm{K}$, Abolfazli-Karizi A. Comparison of transforaminal triamcinolone and dexmedetomidine in radicular low-back pain: A randomized double-blind clinical trial. Anesth Pain Med 2019; 9(5): e96117.

2. Patel VB, Wasserman R, Imani F. Interventional therapies for chronic low back pain: a focused review (efficacy and outcomes). Anesth Pain Med 2015; 5(4): e29716.

3. Rahimzadeh P, Sharma V, Imani F, Faiz HR, Ghodraty MR, NikzadJamnani AR, et al. Adjuvant hyaluronidase to epidural steroid improves the quality of analgesia in failed back surgery syndrome: A prospective randomized clinical trial. Pain physician 2014; 17(1): E75-82.

4. Kim WJ, Shin HY, Yoo SH, Park HS. Comparison of epidural spreading patterns and clinical outcomes of transforaminal epidural steroid injection with high-volume injectate via the subpedicular versus the retrodiscal approach. Pain Physician 2018; 21(3): 269-78

5. Mandell JC, Czuczman GJ, Gaviola GC, Ghazikhanian V, Cho $\mathrm{CH}$. The lumbar neural foramen and transforaminal epidural steroid injections: an anatomic review with key safety considerations in planning the percutaneous approach. AJR Am J Roentgenol 2017; 209(1): W26-35.

6. Ghai B, Gupta AK, Makkar JK, Dhatt SS. Contrast medium volume needed to reach anterior epidural space via the kambin triangle or subpedicular approach for transforaminal epidural injection. Pain Phys 2020; 23(4): 383-92.

7. Hardenbrook M, Lombardo S, Wilson MC, Telfeian AE. The anatomic rationale for transforaminal endoscopic interbody fusion: a cadaveric analysis. Neurosurgical Focus 2016; 40(2): E12-15.

8. Park JW, Nam HS, Cho SK, Jung HJ, Lee BJ, Park Y. Kambin's triangle approach of lumbar transforaminal epidural injection with spinal stenosis. Ann Rehabil Med 2011; 35(6): 833-43.

9. Jeong HS, Lee JW, Kim SH, Myung JS, Kim JH, Kang HS. Effectiveness of transforaminal epidural steroid injection by using a preganglionic approach: a prospective randomized controlled study. Radiol 2007; 245(2): 584-90.

10. Gil HY, Jeong S, Cho H, Choi E, Nahm FS, Lee PB. Kambin's triangle approach versus traditional safe triangle approach for percutaneous transforaminal epidural adhesiolysis using an inflatable balloon catheter: a pilot study. J Clin Med 2019; 8(11): 1996-99.

11. Makkar JK, Gourav KK, Jain K, Singh PM, Dhatt SS, Sachdeva N, et al. Transforaminal versus lateral parasagittal versus midline interlaminar lumbar epidural steroid injection for management of unilateral radicular lumbar pain: a randomized double-blind trial. Pain Phys 2019; 22(6): 561-73.

12. Hwang SM, Son IS, Yang PJ, Kang MS. Preganglionic epidural steroid injection through translateral recess approach. Clin Orthop Surg 2019; 11(1): 131-36.

13. Arici T, Kurçaloğlu M, Eyıgor C, Uyar M. Transforaminal epidural steroid injection and infraneural approach. Agri 2019; 31(2): 104-6

14. Park KD, Lee J, Jee H, Park Y. Kambin triangle versus the supraneural approach for the treatment of lumbar radicular pain. Am J Phys Med Rehabil 2012; 91(12): 1039-50.

15. Park $\mathrm{CH}$, Lee $\mathrm{SH}$, Park HS. Lumbar retrodiscal versus post-ganglionic transforaminal epidural steroid injection for the treatment of lumbar intervertebral disc herniations. Pain Phys 2011; 14(4): 353-60.

16. Jeong HS, Lee JW, Kim SH, Myung JS, Kim JH, Kang HS. Effectiveness of transforaminal epidural steroid injection by using a preganglionic approach: a prospective randomized controlled study. Radiol 2007; 245(2): 584-90.

17. Lee JW, Kim SH, Choi JY, Yeom JS, Kim KJ, Chung SK, et al. Transforaminal epidural steroid injection for lumbosacral radiculopathy: preganglionic versus conventional approach. Korean J Radiol 2006; 7(2): 139-44.

18. Pairuchvej S, Arirachakaran A, Keorochana G, Wattanapaiboon $\mathrm{K}$, Atiprayoon S, Phatthanathitikarn $\mathrm{P}$, et al. The short and midterm outcomes of lumbar transforaminal epidural injection with preganglionic and postganglionic approach in lumbosacral radiculopathy: a systematic review and meta-analysis. Neurosurg Rev 2018; 41(4): 909-16. 